\title{
A PROBABILISTIC APPROACH TO AEROPROPULSION SYSTEM ASSESSMENT
}

\author{
Michael T. Tong \\ National Aeronautics and Space Administration \\ Glenn Research Center \\ Cleveland, Ohio 44135
}

\begin{abstract}
A probabilistic approach is described for aeropropulsion system assessment. To demonstrate this approach, the technical performance of a wave rotor-enhanced gas turbine engine (i.e. engine net thrust, specific fuel consumption, and engine weight) is assessed. The assessment accounts for the uncertainties in component efficiencies/flows and mechanical design variables, using probability distributions. The results are presented in the form of cumulative distribution functions (CDFs) and sensitivity analyses, and are compared with those from the traditional deterministic approach. The comparison shows that the probabilistic approach provides a more realistic and systematic way to assess an aeropropulsion system.
\end{abstract}

\section{INTRODUCTION}

The need to provide cost-effective aeropropulsion technology is critical in today's environment. Since the beginning of the 1990s, civil and military organizations have been attempting to reduce costs like never before. Demands are strong for aircraft engines with reduced life-cycle costs, emphasizing durability for longer intervals between overhaul, high reliability for the lowest possible unscheduled maintenance, and improved maintainability for fast, simple maintenance. In response to such demands of their highly competitive marketplace, the engine manufacturers must focus on product reliability, maintainability, and most definitely affordability. At the same time they must reduce the product development cycle due to shrinking development budgets and resources. Rapid turn around time while investigating new design concepts or technologies is critical to be competitive within the aerospace industry. At the Propulsion System Analysis Office (PSAO) of NASA Glenn Research Center (GRC), our mission is to assess the performance potential and economic benefits of advanced and unconventional propulsion systems for a broad spectrum of subsonic, supersonic, and hypersonic aeronautical vehicles. These assessments provide the basis for NASA's future aeropropulsion program directions and technology investment decisions. As the lead NASA Center in aeropropulsion, GRC's primary mission is aeropropulsion research and technology. The technology is transferred to the aviation industry to help maintain U.S. leadership in the world's aviation market.

In view of the challenges facing the engine manufacturers today, it is obvious that critical decisions must be made in the early stages of engine development where available design freedom can best achieve better performance and cost is relatively low, as shown in Fig. 1. As such, the role of system assessment, performed in the early stages of an engine development program, becomes very critical to the successful development of new aeropropulsion systems. A reliable system assessment not only helps to identify the best propulsion system concept amongst several candidates, it can also identify high payoff technologies worthy of pursuit to decision-makers. This is particularly important for advanced aeropropulsion technology development programs which require enormous amount of resources, such as the Pulse Detonation Engine (PDE) and Supersonic Through-Flow Fan (SSTF) concepts being investigaled at GRC.

In the current practice of deterministic or point-design approach, uncertainties of design variables are either unaccounted for or accounted for by the safety factors. This could often result in an assessment with unknown and unquantifiable reliability. Consequently, it fails to provide additional insight into the risks associated with new technologies, which are often needed by the decision-makers to determine the benefit and return-on-investment of a new aircraft engine. In this paper, an alternative approach based on probabilistic method is described for a comprehensive assessment of aeropropulsion system. The statistical approach quantifies the design uncertainties inherent in a new aeropropulsion system and their influences on engine performance. It provides an analytical framework that allows an engine developer to improve engine performance by determining the necessary design margin, the parameters impacting the uncertainty in performance, and ways to reduce the impact of uncertainty. As such, it enhances the reliability of a system assessment. An assessment of a wave rotor-enhanced turbofan engine is performed to demonstrate the methodology. The assessment accounts for the uncertainties which occur in component efficiencies/flows, and mechanical design variables, using probability distributions.

\section{OBJECTIVE}

The objective of the current work is to demonstrate the application of probabilistic approach and its feasibility for aeropropulsion system assessment.

\section{NUMERICAL EXAMPLE FOR DEMONSTRATION}

A wave rotor-enhanced turbofan engine is chosen to demonstrate the probabilistic approach. Wave rotor is a device that utilizes unsteady 
wave to compress air in a single device. Enhancement of a gas turbine engine with a wave rotor can improve specific power and reduce specilic fuel consumption. This engine was analyzed previously using the traditional deterministic approach, and the results are reported (Jones and Welch, 1996). The intent of the current work is not to challenge the previous results. Rather, it is to demonstrate the application and feasibility of probabilistic approach for aeropropulsion system assessment.

Affordability and return-on-investment of a new aeropropulsion system are strongly influenced by cost, specific fuel consumption, engine thrust and weight. This demonstration focuses on the technical aspect of engine performance, i.e., specific fuel consumplion, engine thrust and weight.

The current results are compared with those calculated previously using the deterministic approach (Jones and Welch, 1996). In addition, the baseline engine used for the comparison with the wave rotor-enhanced engine (Jones and Welch, 1996) is also used for the current comparison.

\section{ANALYSIS APPROACH AND PROCEDURES}

The approach taken in this effort is to combine thermodynamic cycle analysis embedded in the computer code NEPP (NASA Engine Performance Program, Klann and Snyder, 1994), engine weight analysis embedded in the computer code WATE (Onat and Klees, 1979), and fast probability integrator (FPI, Southwest Research Institute, 1995). A schematic of the integrated approach is shown in Fig. 2.

The computer code NEPP is used to calculate engine nel thrust and specific fuel consumption. It is a one-dimensional steady state thermodynamic cycle analysis code which allows the user to model virtually any kind of gas turbine engine cycle through the use of components which can be placed in any order to create the desired cycle. The engine weight is estimated by the WATE code. These analyses are performed at the sealevel static condition. The role of FPI is to perform probabilistic analysis utilizing the results generated by NEPP and WATE. The results are presented in the form of cumulative distribution functions (CDFs). In addition, FPI is used to perform sensitivity analysis to rank design variables in order of their impact on a specific response variable. The FPI code was developed under contract with NASA Glenn Research Center.

Sensitivity values could be \pm in nature. A positive value indicales that the response variable will decrease as the design variable increases and vice versa. Variable with the highest absolute sensitivity value is defined to be the most influential variable. Variable with the second highest absolute sensitivity value is second most influential variable and so on. This ranks the design variables in the order of their influences on the response variable. The sensitivity information thus obtained from FPI is very useful from the design point of view. For example, reliability in design can be improved when uncertainties in the most influential variables are reduced. Those design variables that do not have significant influences deterministically could nevertheless have strong influences on the response scatter if these design variables have large uncertainties. Weak design variable with large uncertainties may have probabilistic sensitivity factors more important than strong design variables with small uncertainties. Unlike deterministic analysis, sensitivity factors in probabilistic analysis are functions of both the deterministic sensitivity and the uncertainty (characterized by the standard deviation).

The procedures for the probabilistic analysis are as follows:

(1) Identify design variables with uncertainties (i.e. identify the risk elements).
(2) Quantify the uncertainties with probability distributions, based on expert opinion elicitation, historical data, or benchmark/ prototype testing, etc.

(3) Perform perturbation for the selected set of values (mean and standard deviation) of the design variables to generate response variables. For this work, NEPP and WATE are used to perturb specific fuel consumption (SFC), engine thrust and weight.

(4) Perform probabilistic analysis to compute CDFs of the response variables. For this work, FPI is used to compute the CDFs and the corresponding sensitivities of the response variables and rank the design variables in the order of their influences.

\section{PROBABILISTIC SIMULATION}

There are a number of approaches available for obtaining probabilistic response for a given set of independent primitive variables. One approach that is commonly used is called Monte-Carlo simulation technique. While this approach provides almost exact solutions, it is fairly expensive and time-consuming approach. In this technique, randomly selected values of the input variables, which are based on their known probabilistic distributions, are used to deterministically compute the value of the response variable. This has to be repeated usually several hundreds or even thousands of times to build the response probabilistic characteristics. In essence, this technique requires a large number of simulations to generate CDF"s of output variables. Although, inherently simple, the large number of computer runs required to obtain a reasonably accurate CDF of output variables becomes its obvious disadvantage. NASA-Glenn Research Center has been involved in developing efficient probabilistic methods for more than a decade. As a result of this research initiative, fast probability integration (FPI) algorithms were developed (Aerospace System Design Laboratory, 1996) to solve a large class of engineering problems.

Let us say that there are $n$ random design variables in a problem and that we want to use probabilistic analysis to compute the probability of occurrence of a certain response function

$$
Z(X)=Z\left(X_{1}, X_{2}, \ldots X_{n}\right)
$$

where $Z$ represents the response variable and $X$ represents the random variable. Our aim is to compute the probability that $Z$ will have a value less than or equal to a given magnitude $Z_{0}$. To achieve this goal, the performance function, which describes how the mechanics of the system behaves, can be cast as a limit state function $g(X)$, which can bc described as

$$
g(X)=Z(X)-Z_{0}
$$

Traditionally, the limit state function $\mathrm{g}$ has been defined in such a way that $g=0$ represents a boundary where $g<0$ represents failed region and $g>0$ represents safe region. Here the objective would be to compute $P[g(X) \leq 0]$. Generally speaking, $Z_{0}$ describes a limit indicating failure; $g(X)$ is called a failure function.

Given the joint probability density function $f_{x}(x)$ of the limit state function $g(x)$, we can formulate the limit state probability $P[g \leq 0]$ as

$$
P_{f}=P[g(X) \leq 0]=\int_{\Omega} \ldots \int f_{x}(x) d x
$$


where $\Omega$ describes the domain of integration. This multiple integration is, in general, very difficult to integrate analytically. However, FPI has been found to be an excellent tool to evaluate Eq. (3) efficiently and accurately.

\section{DESIGN AND RESPONSE VARIABLES FOR THE NUMERICAL EXAMPLE}

The design variables are:

\author{
fan efficiency \\ low pressure compressor (LPC) efficiency \\ high pressure compressor (HPC) efficiency \\ wave rotor pressure ratio \\ high pressure turbine (HPT) efficiency \\ high pressure turbine (HPT) inlet temperature \\ low pressure turbine (LPT) efficiency \\ bleed flow \\ turbine disk material strength
}

The assumed mean values and standard deviations of these design variables are shown in Table 1. These variables are assumed to be independent and have normal distributions, with the exception of the turbine disk material strength which has Weibull distribution. For many engincering problems, design variables with small variability have generally been seen to have normal distributions. Material strength is generally characterized with Weibull distributions. With upper and lower limits for these design variables based on (2 standard deviations around the mean value for each design variable, 95.4 percent of the expected uncertainty is captured

\section{The response variables are: engine net thrust specific fuel consumption (SFC) engine weight}

\section{RESULTS AND DISCUSSION}

As mentioned earlier, it is critical to assess the reliability of a new aeropropulsion system because of inherent design uncertainties. The current demonstration focuses on the technical aspect of engine performance, i.e., specific fuel consumption, engine thrust and weight. The results are presented in the form of cumulative distribution functions (CDFs) and sensitivity analyses. A CDF gives a relationship between a value up to certain magnitude of a response variable and the probability of its occurrence.

The results are summarized and compared with those based on the deterministic approach, in Table 2.

In reference to the SFC obtained previously using the deterministic approach, $0.304 \mathrm{Jb} / \mathrm{hr} / \mathrm{lb}(0.0310 \mathrm{~kg} / \mathrm{hr} / \mathrm{N})$, the current result shows that the cumulative probability for that to occur is only 10 percent. In other words, the confidence level to achieve a SFC of $0.304 \mathrm{lb} / \mathrm{hr} / \mathrm{lb}$ $(0.0310 \mathrm{~kg} / \mathrm{hr} / \mathrm{N})$ or better is only 10 percent. The probability is much higher to obtain a SFC of $0.316 \mathrm{lb} / \mathrm{hr} / \mathrm{lb}(0.0322 \mathrm{~kg} / \mathrm{hr} / \mathrm{N})$ or better, about 95 percent. This is shown in Fig. 3.

The sensitivity of SFC to the nine design variables is shown in Fig. 4. It shows that the most influential design variable for SFC is highpressure turbine (HPT) inlet temperature. It implies that to improve the SFC of this engine, the biggest payoff is to decrease the HPT inlet temperature and control its scatter (uncertainties). By reducing the mean temperature from $3200 \mathrm{R}(1778 \mathrm{~K})$ lo $3160 \mathrm{R}(1755 \mathrm{~K})$, the SFC reduces from $0.309 \mathrm{lb} / \mathrm{hr} / \mathrm{lb}(0.0315 \mathrm{~kg} / \mathrm{hr} / \mathrm{N})$ to $0.306 \mathrm{lb} / \mathrm{hr} / \mathrm{lb}(0.0312 \mathrm{~kg} / \mathrm{hr} / \mathrm{N})$ at 50 percent probability level. This result is also shown in Fig. 3. In addition, by reducing the uncertainty of the HPT inlet temperature from $\pm 100 \mathrm{R}(56 \mathrm{~K})$ to $\pm 50 \mathrm{R}(28 \mathrm{~K})$, the scatter range of the SFC is reduced by 30 percent. This is indicated by the probability density function (PDF) shown in Fig. 5. The influences of HPT and LPT efficiencies are moderate. Other design variables such as LPC and HPC efijiciencies, and wave rotor pressure ratio have minimal influences. As expected, the turbine disk material strength has no influence on SFC.

For the engine net thrust, the result shows that the probability to obtain an engine net thrust of $89470 \mathrm{lbs}(398 \mathrm{kN})$ or higher, which was reported (Jones and Welch, 1996) based on the deterministic approach, is fairly good-about 60 percent (1.0 to 0.4). This is shown in Fig. 6 . Also, even with the current assumption of design uncertainties, it is very likely that the current engine will outperform the baseline engine in net thrust-about 90 percent probability. This is also shown in Fig. 6. The sensitivity results for engine net thrust is shown in Fig. 7. Again, the result shows that the most influential design variable for engine net thrust is HPT inlet temperature, and the turbine disk material strength has no impact.

For the engine weight, the likelihood of obtaining an engine weight of $21120 \mathrm{lbs}(9580 \mathrm{~kg}$ ) or less, calculated deterministically (Jones and Welch, 1996), is fairly good-about 66 percent. However, with the current assumption of design uncertainties it is very unlikely that the current engine will outperform the baseline engine in engine weight-only about 10 percent probability. These results are shown in Fig. 7. The sensitivity results for engine weight is shown in Fig. 8. As expected, the result shows that the turbine disk material strength has significant impact on the engine weight. The material strength, logether with HPT inlet temperature and HPC efficiency, are the three most influential design variables. The rest of the design variables have moderate influences.

Overall, the results show that component uncertainty can have a significant impact on engine performance. For the current example, the HPT inlet temperature dominates the influence on SFC and engine thrust. Its impact on engine weight is more moderate, since other design variables such as turbine-disk material strength and HPC efficiency also have significant impact on engine weight. Decreasing the HPT inlet temperature will have favorable impact on SFC but unfavorable impact on engine thrust and weight, and vice versa. If $\mathrm{SFC}$ receives too much emphasis, engine thrust and weight suffer. However, increasing the turbine-disk material strength and/or component efficiencies can compensate the unfavorable impact on engine weight. Discovering these relationships is not peculiar to using probabilistic approach. Rather, probabilistic approach helps engine developers visualize and make trades of design margins.

More over, the results show that the current integrated probabilistic approach (NEPP + WATE + FPI) not only calculates the SFC, engine thrust and weight, but also determines the probability of their occurrences. As such, the probabilistic assessment provides additional insight into the risks associated with new technologies, which makes it easier for the decision-makers to determine the benefit and return-oninvestment of a new acropropulsion system. In addition, the approach ranks the relative importance of the design variables as to their influences on the engine performance, in the form of sensitivity factors. High sensitivity factor indicates an area to be focused for improving the engine performance and its reliability 
The current work addresses the application of probahilistic approach to assess SFC, engine thrust and weight. Similarly, the approach can also be used to assess the other aspects of aeropropulsion system performance, such as cost, acoustic noise, and emissions, etc.

\section{CONCLUSIONS}

Based on the comparison of the results between the probabilistic and deterministic approaches, the following conclusions are made:

(1) The probabilistic approach provides a more realistic and systematic way to assess an aeropropulsion system, because it accounts for uncertainties in the design variables.

(2) The results from probabilistic assessment are more credible and reliable, because it incorporates the 'past lessons learned' (i.c., expert opinions, historical data, etc.) to quantify the risks. In addition, the likelihood of repeating past mistakes will be minimized.

(3) The probabilistic approach allows the decision-makers to detect problems early before they become critical. As such, resources (time, funding, etc.) can be used more wisely.

(4) Probabilistic assessments provide decision makers with a tool that allows them to assign priorities to needed technological developments and thus increase the likelihood that R\&D investments will have high payolfs.
(5) The probabilistic assessment provides additional insight into the risks associated with new technologies, which makes it easier for the decision-makers to determine the benefit and return-oninvestment of a new aeropropulsion system.

\section{ACKOWLEDGEMENT}

The author would like to acknowledge the comments made by Mr. Scott Jones of NASA Glenn Research Center, Dr. Subodh Mital of University of Toledo, and Dr. Michael Shiao of Federal Aviation Administration.

\section{REFERENCES}

Jones, S.M. and Welch, G.E.: Performance Benefits for Wave Rotol-Topped Gas Turbine Engines, NASA TM-107193, 1996.

Klann, J.L., Snyder, C.A.: NEPP Programmers Manual (NASA Engine Performance Program), Vols. I and II, NASA TM-106575, 1994.

Onat, E. And Klees, G.W.: A Method to Estimate Weight and Dimensions of Large and Small Gas Turbine Engines, NASA CR-I59481, 1979.

Southwest Research Institute: FPI User's and Theoretical Manual, San Antonio, TX, 1995.

Aerospace System Design Laboratory, Georgia Institute of Technology: Research Opportunities in Engineering Design, NSF Strategic Planning Workshop Final Report, April, 1996. 
TẢBLE 1.-Wave Rotor-Enhanced Turbofan Engine

Design Variables with Uncertainties

\begin{tabular}{|l|c|c|c|c|}
\hline \multicolumn{1}{|c|}{ Design variable } & $\begin{array}{c}\text { Determinislic } \\
\text { approach } \\
\text { (from Ref 1) }\end{array}$ & Mean & $\begin{array}{c}\text { Scatter } \\
\text { range }\end{array}$ & $\begin{array}{c}\text { Distribution } \\
\text { yype }\end{array}$ \\
\cline { 3 - 5 } & 0.91 & 0.91 & \pm 0.02 & Normal \\
LPC efficiency & 0.88 & 0.87 & \pm 0.02 & Normal \\
HPC efficiency & 0.85 & 0.87 & \pm 0.02 & Normal \\
Wave rotor pressure ratio & 1.15 & 1.13 & \pm 0.02 & Normal \\
HPT efficiency & 0.89 & 0.88 & \pm 0.02 & Normal \\
HPT inlet temperature & $3200 \mathrm{R}(1778 \mathrm{~K})$ & $3200 \mathrm{R}(1778 \mathrm{~K})$ & $\pm 100 \mathrm{R}( \pm 56 \mathrm{~K})$ & Normal \\
LPT efficiency & 0.93 & 0.91 & \pm 0.02 & Normal \\
Bleed flow, percent & 19.5 & 19.0 & \pm 1.0 & Normal \\
Turbine disk material strength & $100 \mathrm{ksi}$ & $100 \mathrm{ksi}$ & $\pm 10 \mathrm{ksi}$ & Weibull \\
& $(690 \mathrm{MPa})$ & $(690 \mathrm{Mpa})$ & $(69 \mathrm{Mpa})$ & \\
\hline
\end{tabular}

\begin{tabular}{|c|c|c|}
\hline \multicolumn{3}{|c|}{ Other Design Variables } \\
\hline Design variable & Deterministic approach & Probabilistic approach \\
\hline Inlet flow & \multicolumn{2}{|c|}{$2800 \mathrm{Jb} / \mathrm{s}(1270 \mathrm{~kg} / \mathrm{s})$} \\
\hline Inlet recovery & \multicolumn{2}{|c|}{1.00} \\
\hline Inlet temperature & \multicolumn{2}{|c|}{$545.7 \mathrm{R}(303 \mathrm{~K})$} \\
\hline Bypass ratio & \multicolumn{2}{|c|}{7.00} \\
\hline Fan pressure ratio & \multicolumn{2}{|c|}{1.59} \\
\hline Fan corrected flow & \multicolumn{2}{|c|}{$2875 \mathrm{lb} / \mathrm{s}(1304 \mathrm{~kg} / \mathrm{s})$} \\
\hline LPC pressure ratio & \multicolumn{2}{|c|}{1.55} \\
\hline HPC pressure ratio & \multicolumn{2}{|c|}{15.8} \\
\hline Wave rotor temp ratio & \multicolumn{2}{|c|}{1.91} \\
\hline
\end{tabular}


TABLE 2.-Performance of the Wave Rotor-Enhanced Turbofan Engine

Comparison of Results between Probabilistic and Deterministic Approaches

\begin{tabular}{|c|c|c|}
\hline Ellgine performance & $\begin{array}{c}\text { Deterministic approach } \\
\text { (from Ref. I) }\end{array}$ & Probabilistic approach \\
\hline Specific fuel consumption & $\begin{array}{l}0.304 \mathrm{lb} / \mathrm{hr} / \mathrm{lb} \\
(0.0310 \mathrm{~kg} / \mathrm{hr} / \mathrm{N})\end{array}$ & $\begin{aligned} \leq 0.304 \mathrm{lb} / \mathrm{hr} / \mathrm{lb}(0.0310 \mathrm{~kg} / \mathrm{hr} / \mathrm{N}) \quad 10 \% \text { probability } \\
\leq 0.309 \mathrm{lb} / \mathrm{hr} / \mathrm{lb}(0.0315 \mathrm{~kg} / \mathrm{hr} / \mathrm{N}) \quad 50 \% \text { probability } \\
\leq 0.316 \mathrm{lb} / \mathrm{hr} / \mathrm{lb}(0.0322 \mathrm{~kg} / \mathrm{hr} / \mathrm{N}) \quad 95 \% \text { probability } \\
\text { Median value }=0.309 \mathrm{lb} / \mathrm{hr} / \mathrm{lb}(0.0315 \mathrm{~kg} / \mathrm{hr} / \mathrm{N})\end{aligned}$ \\
\hline Engine net thrust & $\begin{array}{l}89470 \mathrm{lbs} \\
(398 \mathrm{kN})\end{array}$ & $\begin{array}{c}\geq 89470 \mathrm{lbs}(398 \mathrm{kN}) \quad 60 \% \text { probability } \\
\geq 90114 \mathrm{lbs}(40 \mathrm{kN}) \quad 50 \% \text { probability } \\
\geq 85997 \mathrm{lbs}(383 \mathrm{kN}) \quad 95 \% \text { probability } \\
\text { Median value }=90114 \mathrm{lbs}(401 \mathrm{kN}) \\
\end{array}$ \\
\hline Engine weight & $\begin{array}{l}21120 \mathrm{lbs} \\
(9580 \mathrm{~kg})\end{array}$ & $\begin{array}{l}\leq 21120 \mathrm{lbs}(9580 \mathrm{~kg}) \quad 66 \% \text { probability } \\
\leq 20952 \mathrm{lbs}(9504 \mathrm{~kg}) \quad 50 \% \text { probability } \\
\leq 21650 \mathrm{lbs}(9820 \mathrm{~kg}) \quad 95 \% \text { probability } \\
\text { Median value }=20952 \mathrm{lbs}(9504 \mathrm{~kg})\end{array}$ \\
\hline
\end{tabular}

Note: *All engine weight calculations include the weight of the wave rolor, estimated to be $1650 \mathrm{lbs}$ $(748 \mathrm{~kg})$ in Ref. 1. 


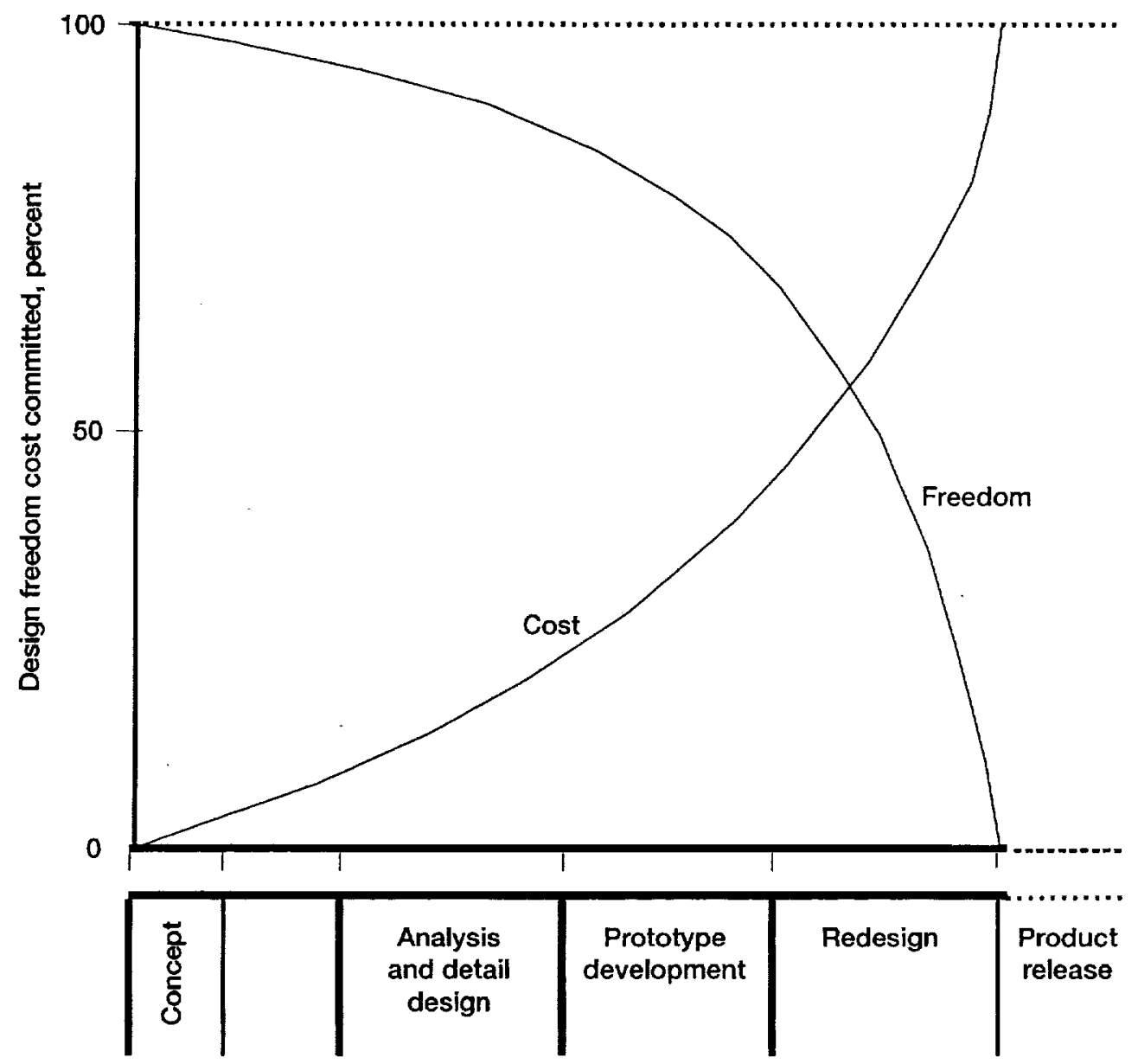

Figure 1.-Design process paradigm (from reference 5). 


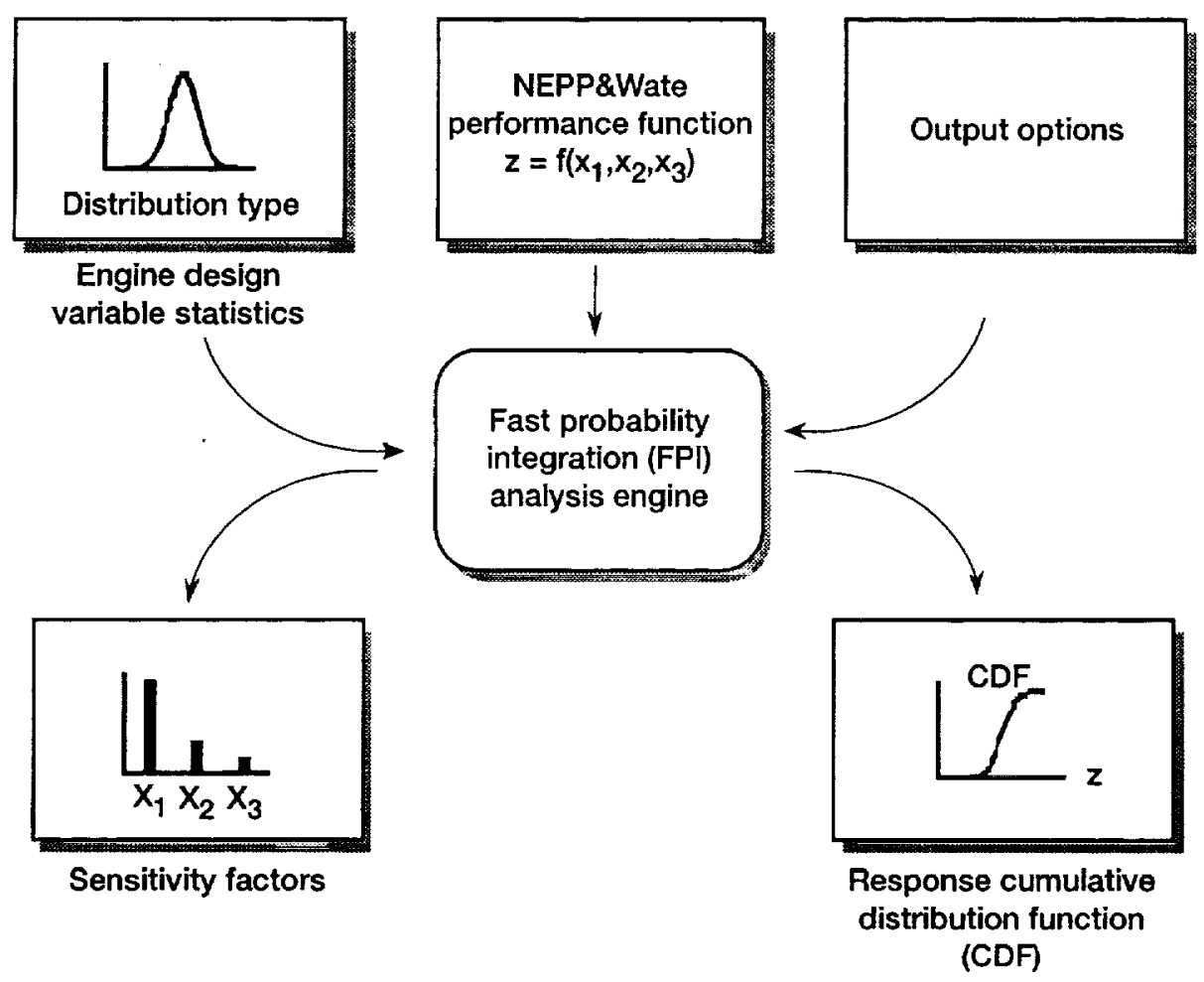

Figure 2.-Fast probability integration input/output schematic. 


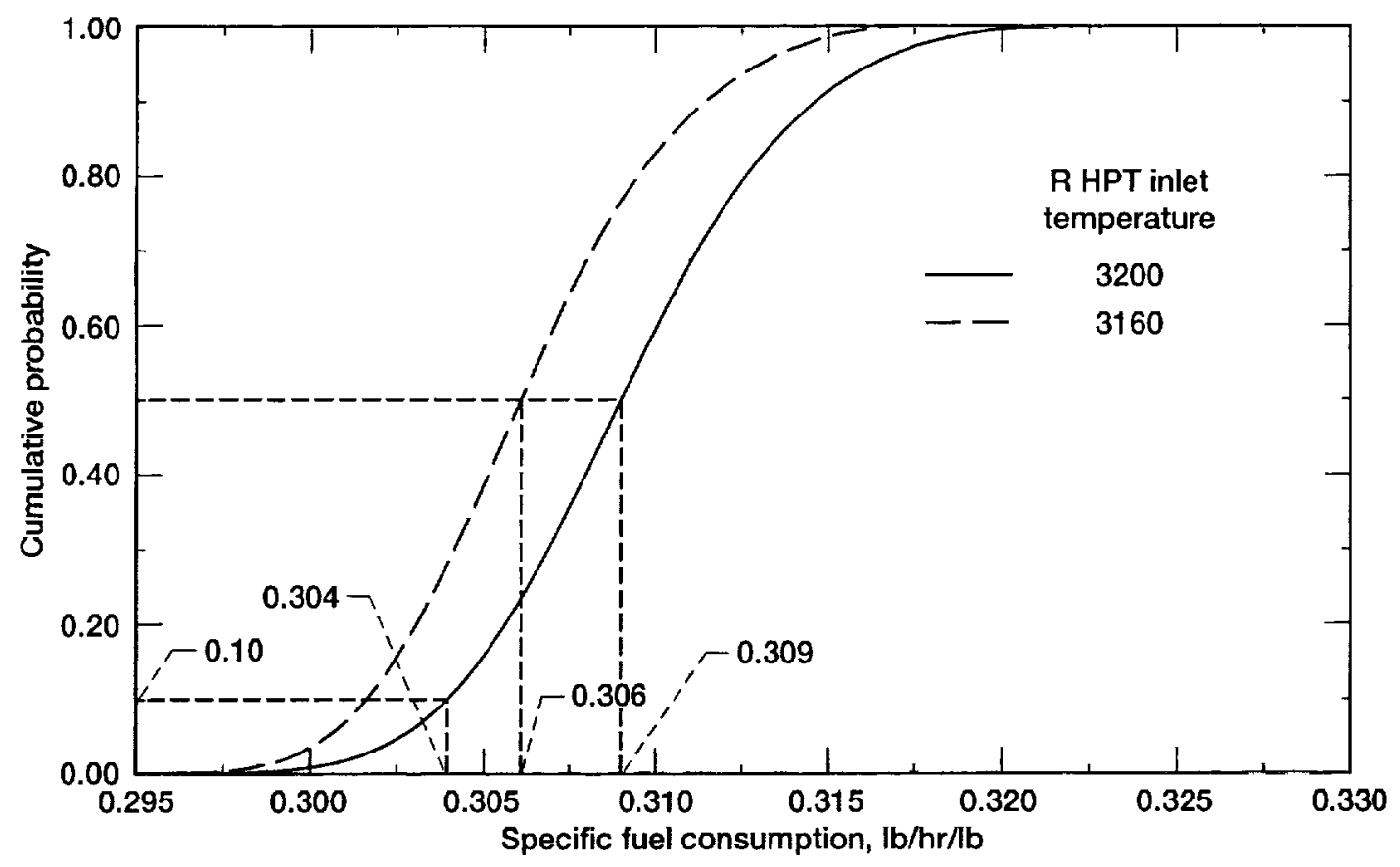

Figure 3.-CDF of wave rotor-enhansed turbofan engine SFC. 


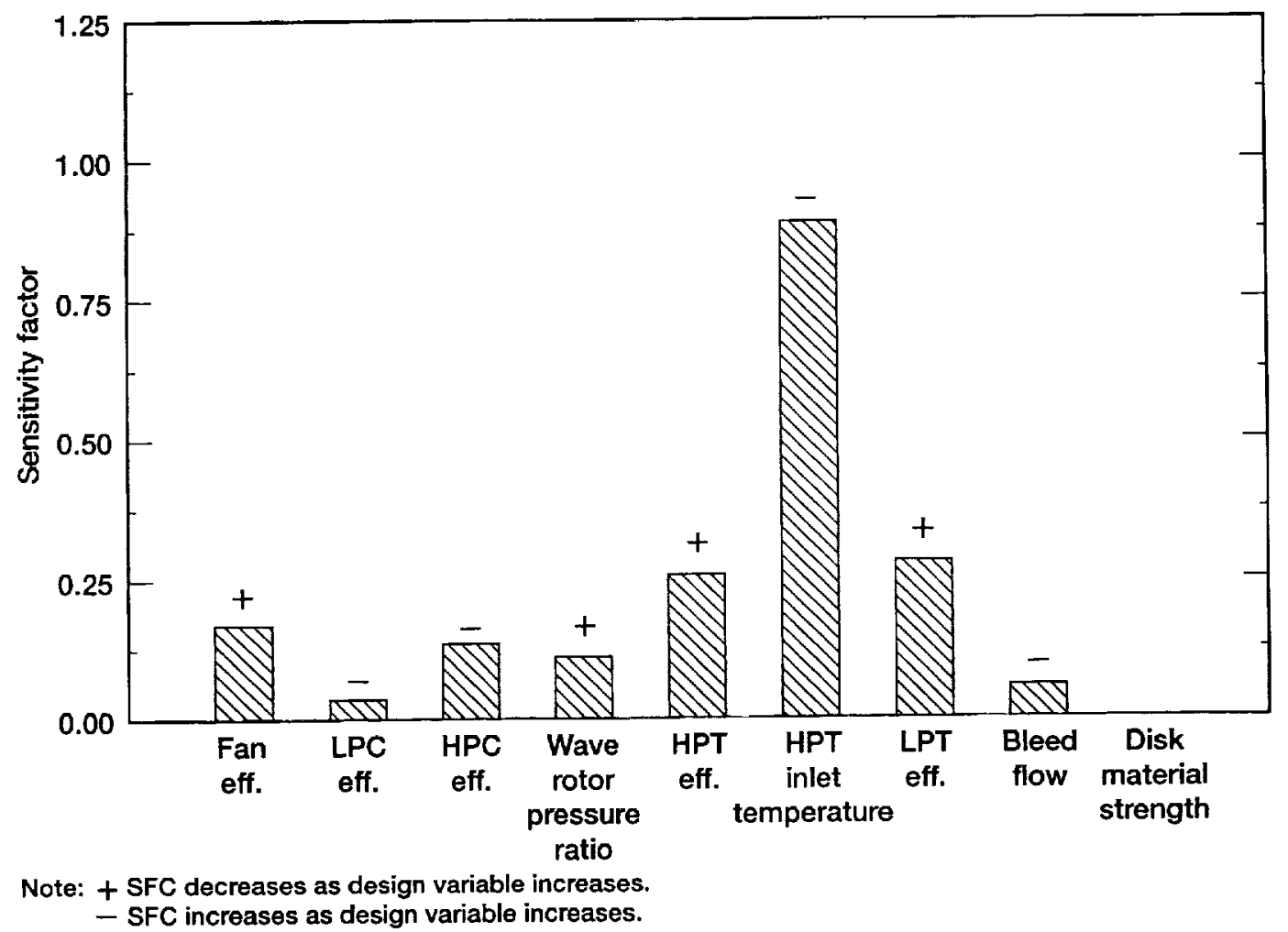

Figure 4.-Sensitivity of specific fuel consumption. 


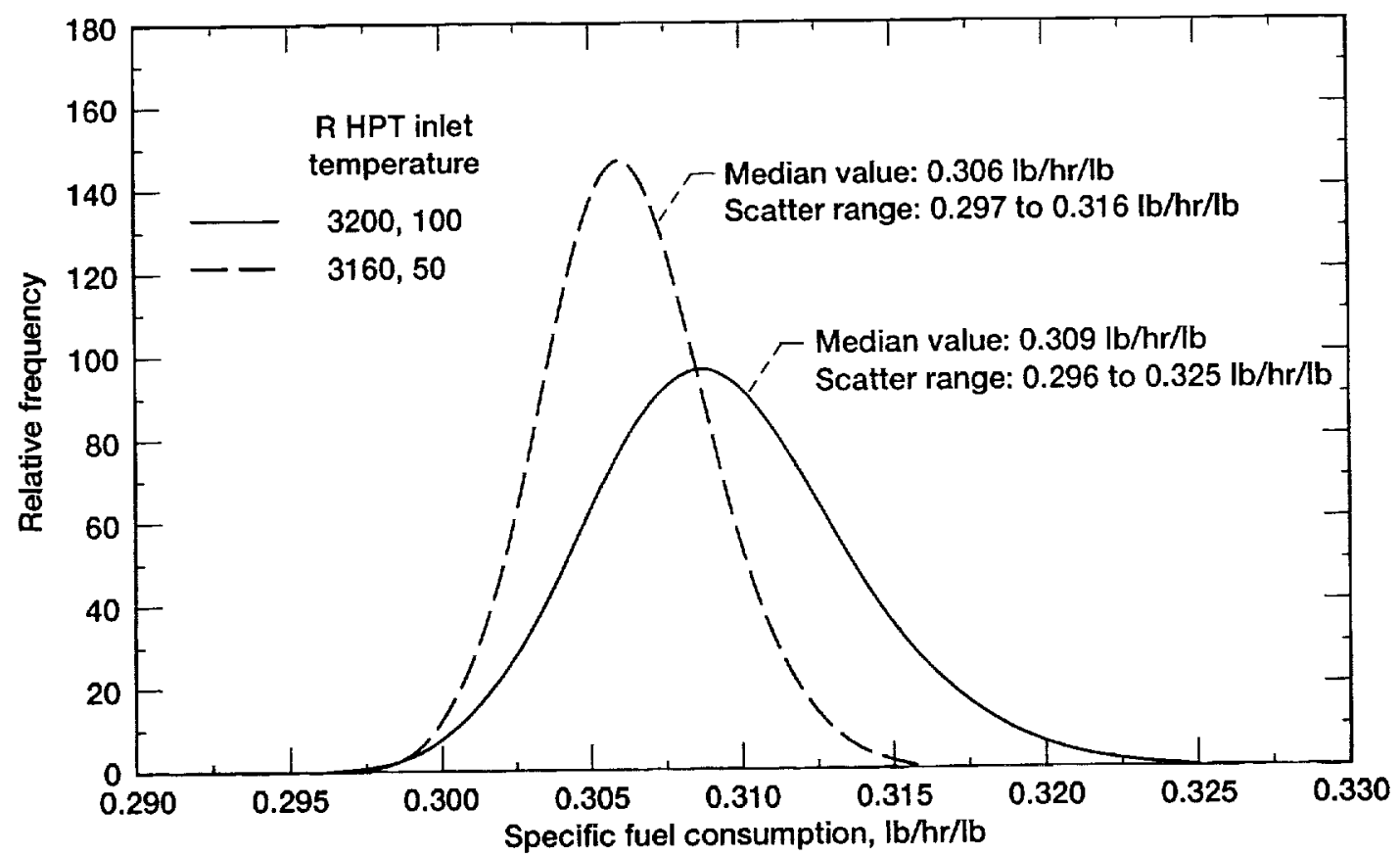

Figure 5.-PDF of wave rotor-enhansed turbofan engine SFC. 


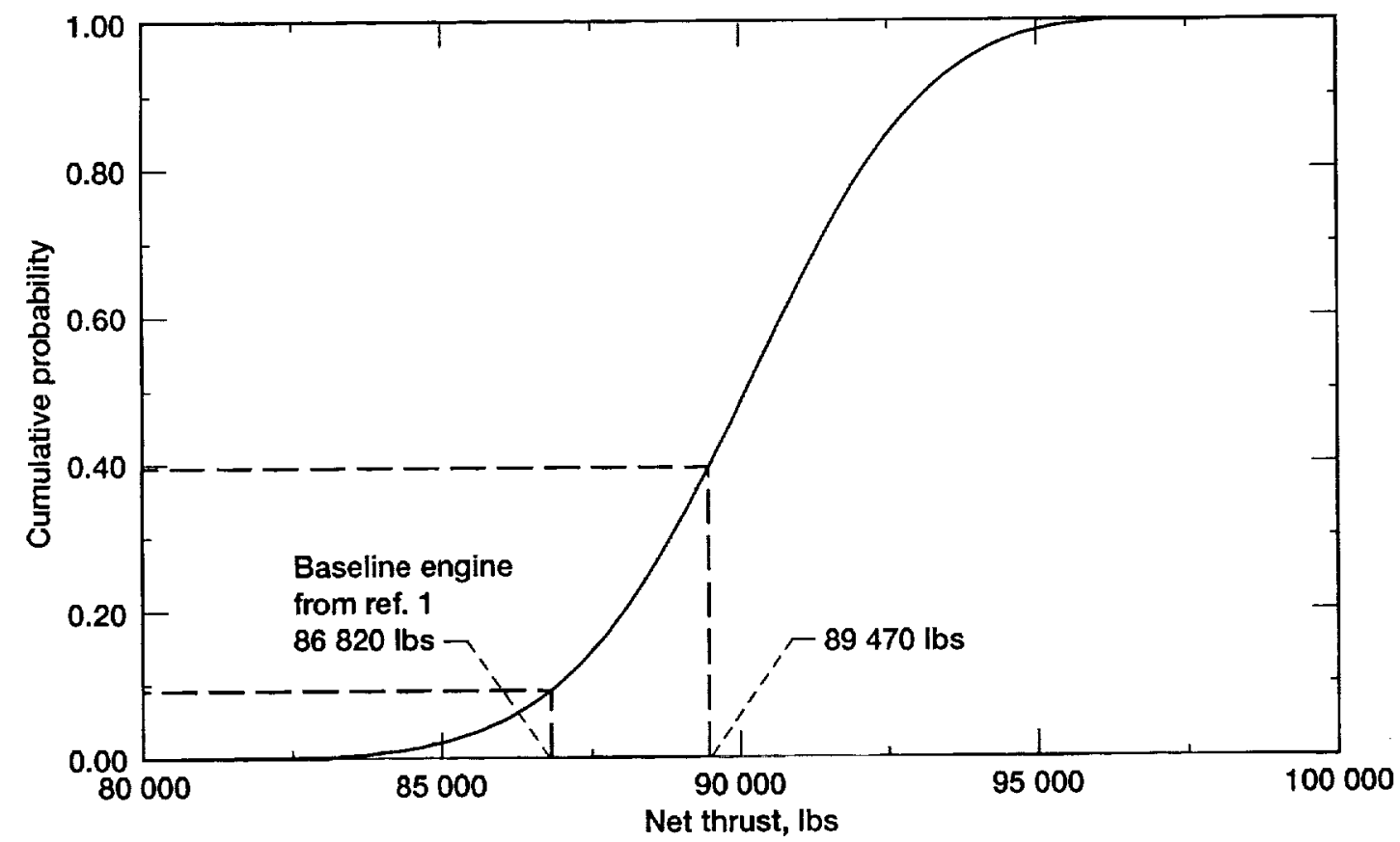

Figure 6.-CDF of wave rotor-enhansed turbofan engine net thrust. 


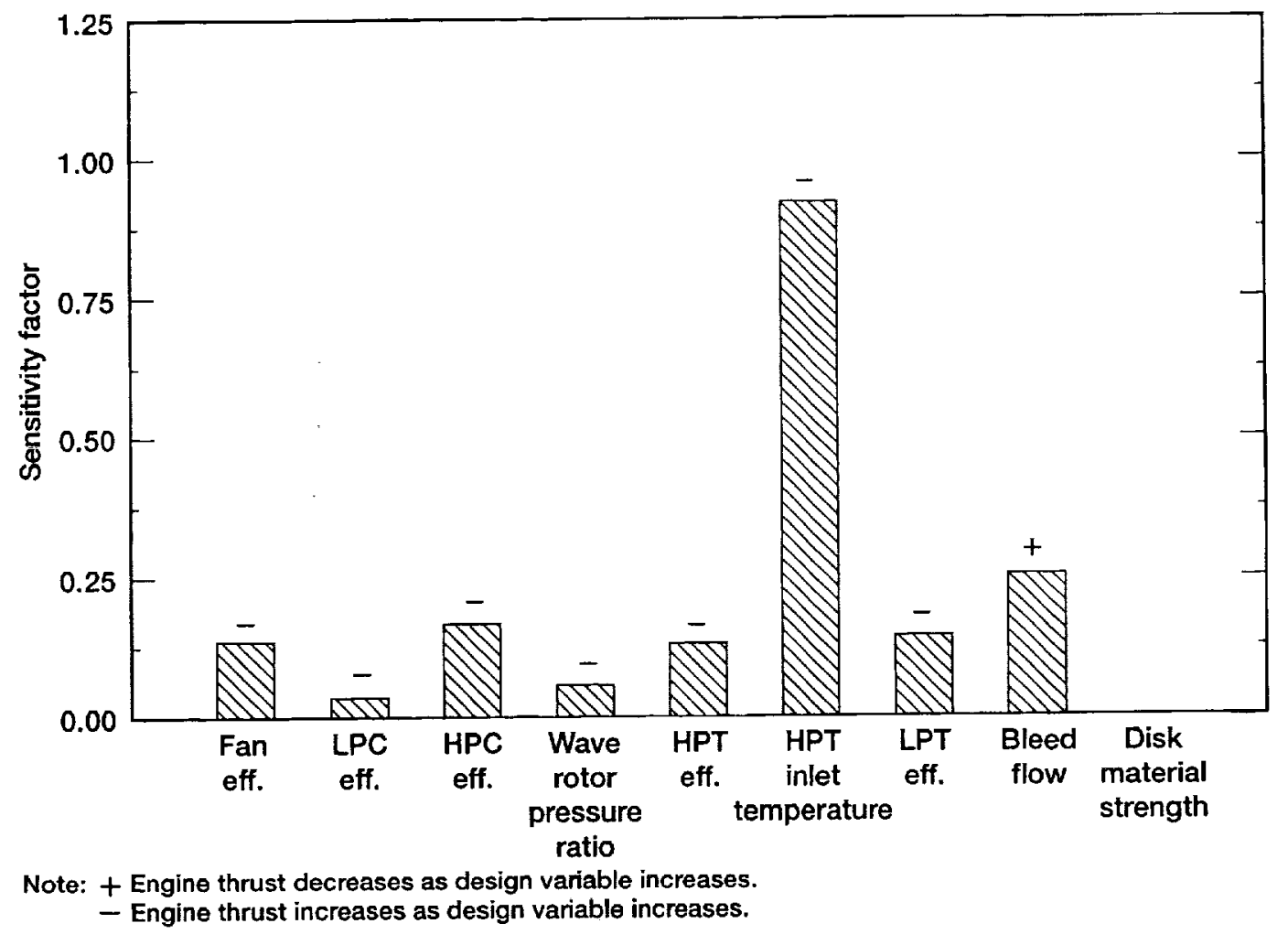

Figure 7.-Sensitivity of engine net thrust. 


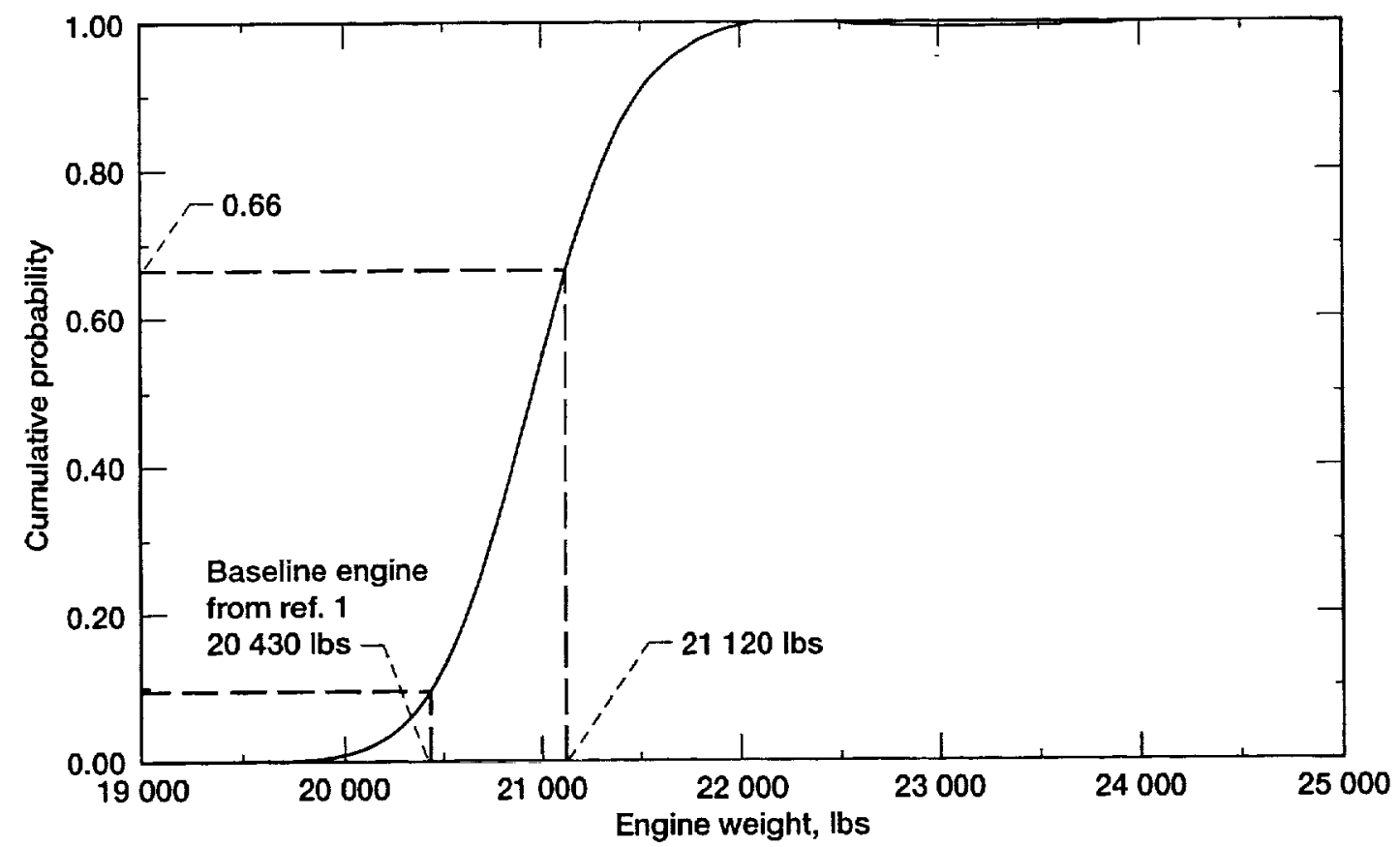

Figure 8.-CDF of wave rotor-enhansed turbofan engine weight. 


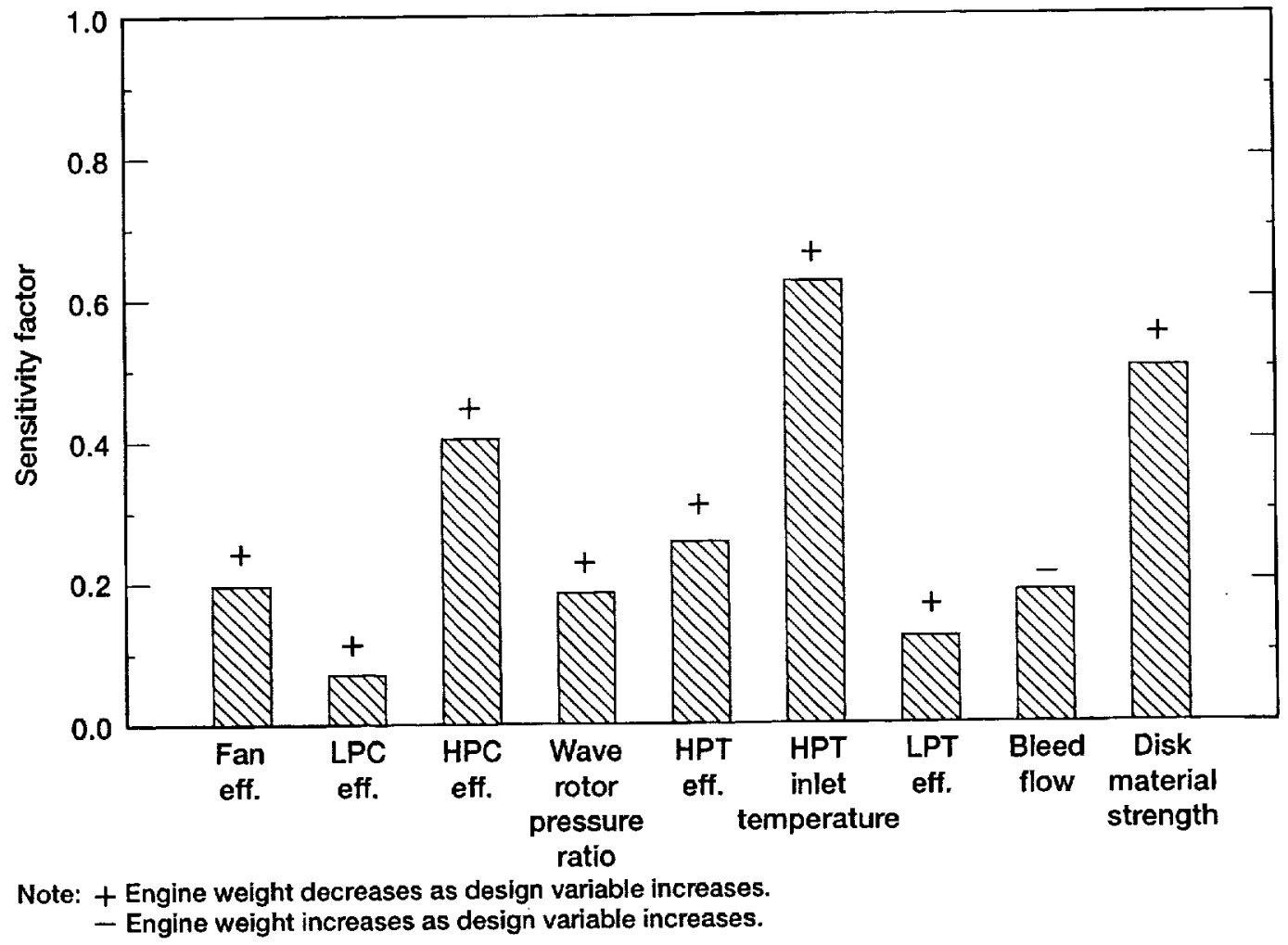

Figure 9.-Sensitivity of engine weight. 